\title{
Differential Treatment Response to Insulin Intensification Therapy: A Post Hoc Analysis of a Randomized Trial Comparing Premixed and Basal-Bolus Insulin Regimens
}

\author{
Li Xin Shi · Peng Fei Li · Jia Ning Hou (D
}

Received: April 21, 2017 / Published online: June 30, 2017

(c) The Author(s) 2017. This article is an open access publication

\begin{abstract}
Introduction: Identification of subgroups of patients that may benefit most from certain treatment is important because individual treatment response varies due to multiple contributing factors. The present study used the subgroup identification based on the differential effect search (SIDES) algorithm to identify subgroups with different treatment responses to insulin intensification therapies.

Methods: This was a post hoc analysis of a 24-week, multicenter, open-label, randomized, parallel study comparing prandial premixed therapy (PPT) to basal-bolus therapy (BBT). Patients with type 2 diabetes mellitus were randomized to PPT (insulin lispro mix 50/50 thrice daily with meals) or BBT (glargine at bedtime plus mealtime insulin lispro) insulin intensification therapies. The SIDES algorithm was used to identify the subgroups from at-goal
\end{abstract}

Enhanced content To view enhanced content for this article go to http://www.medengine.com/Redeem/ 30A8F060401F68C0.

L. X. Shi

Department of Endocrinology and Metabolism, Affiliated Hospital of Guiyang Medical College,

Guiyang 550004, China

P. F. Li · J. N. Hou (ه)

Medical Department, Lilly Suzhou Pharmaceutical

Co. Ltd, Shanghai 200021, China

e-mail: hou_jia_ning@lilly.com patients [glycated hemoglobin (HbA1c) $<7.0 \%$ $(53.0 \mathrm{mmol} / \mathrm{mol})$ at the end of 24 weeks; $n=182]$ who could have benefitted from insulin intensification therapies.

Results: Baseline characteristics of overall at-goal patients were comparable between PPT and BBT groups. The SIDES algorithm identified patients with race other than Caucasian (i.e., African-American, Asian, and Hispanic) and baseline fasting blood glucose (FBG) $<8.89 \mathrm{mmol} /$ $\mathrm{L}$ as a subgroup that could respond better to PPT relative to BBT than the overall at-goal patient population. In this identified subgroup population, the HbA1c mean (standard deviation) changes from baseline to endpoint in PPT and BBT groups were $-2.27(0.88) \%$ versus $-2.05(0.75) \%$; $p=0.40$, respectively; while in the overall at-goal patients, the HbA1c changes were $-2.17(0.79) \%$ versus $-2.34(1.00) \%$; $p=0.19$, respectively.

Conclusions: The preliminary results showed that the subgroup of patients with race other than Caucasian and FBG $<8.89 \mathrm{mmol} / \mathrm{L}$ may respond better to premixed intensification therapy. This result provides some preliminary information for further investigation in prospective studies.

Funding: Eli Lilly and Company.

Clinical Trial Registration: Clinicaltrials.gov ID number: NCT00110370.

Keywords: Basal-bolus; Differential treatment response; Premixed insulin; SIDES algorithm; Type 2 diabetes mellitus 


\section{INTRODUCTION}

By 2040, the prevalence of type 2 diabetes mellitus (T2DM) is estimated to be 642 million cases (10.4\%) across the globe [1]. T2DM is a serious health epidemic with multiple contributing factors, including but not limited to diet, lifestyle, and genetic predisposition [2].

Insulin therapy is recommended to compensate for inadequate insulin secretion due to progressive pancreatic beta cell dysfunction after failure on oral antihyperglycemic medications (OAMs) and to combat a worsening glycemic profile. Intensive insulin therapy is recommended in patients who have failed previous insulin therapy, and two main options of intensification are basal-bolus and premixed insulin regimens [3, 4]. According to 2017 American Diabetes Association (ADA) guidelines [5], premixed insulin, thrice daily, is recommended as intensification therapy when glycated hemoglobin (HbA1c) could not be controlled with premixed insulin twice-daily regimen. The guidelines also suggested switching patients from premixed analogue insulin thrice daily to basal-bolus regimen or vice versa if HbA1c targets are not being met and depending on other patient considerations. Intensive glycemic control reduces microvascular and macrovascular complications. However, multiple contributing factors, such as genetic variations and clinical, sociodemographic, comorbidity, and behavioral factors, may affect the outcome of the antidiabetic treatment $[6,7]$. Hence, choosing an optimal insulin intensification therapy is important and needs exploration.

In clinical trials, the overall or average treatment effect in the study population may not reflect the subgroup and/or individual treatment outcomes. The overall or average treatment effect obscures the individual meaningful benefits or risks, or both, because some patients may have more beneficial outcomes than average from treatment, whereas others do not benefit from treatment or may be harmed [8]. In this regard, identification of patient subgroups that can benefit the most from certain treatments is of clinical importance for patients and physicians. Thus, personalized medicine or tailored therapeutics has been developed, leading to a substantial improvement in the ratio of benefits to risks for this set of patients.

There are multiple approaches for this required subgroup identification. We can predefine the subgroups with commonly used cutoff values like age of patients (e.g., 60 or 65 years), but the actual cutoff will be data-driven. The other most commonly used subgroup cutoff is median (or quartiles) of the interested factors. Though these two approaches can explore the subgroups of a predefined feature, they fail to identify the subgroup of interest that derives greater benefit compared to the whole population. There has always been a need to identify such subgroups quickly and efficiently. In this analysis, we applied the subgroup identification based on the differential effect search (SIDES) algorithm to identify patient subgroups that may benefit more from the prandial premixed therapy (PPT) than from basal-bolus therapy (BBT) in the at-goal patient population that had responded to these treatments [achieved $<7.0 \%$ $(53.0 \mathrm{mmol} / \mathrm{mol}) \mathrm{HbA} 1 \mathrm{c}$ at the end of treatment period]. SIDES is a novel recursive partitioning method used to identify subgroups of patients with enhanced treatment effects based on a differential effect search algorithm [9].

Identification of subgroups of patients that may benefit most from specific treatment is important for individualized therapy. The present study used the SIDES algorithm to identify subgroups with different treatment responses to insulin intensification therapies. This was the first analysis that used the SIDES algorithm to identify patient subgroups that may respond better to PPT than to BBT. Knowing the subgroup that responds better to specific insulin intensification treatment may provide guidance in generating a preliminary hypothesis to explain heterogeneity that could be tested in confirmatory, prospective, randomized clinical trials. 


\section{METHODS}

\section{Study Design}

These results were a post hoc analysis of a 24 -week, multicenter, open-label, randomized, parallel, active-controlled study comparing PPT with BBT [10].

This study included patients (a) with T2DM (b) who were 30-75 years of age, inclusive, at the time of screening, (c) who had been treated for at least 90 days with insulin glargine once daily ( $\geq 30 \mathrm{U} /$ day) in combination with OAMs (sulfonylurea or meglitinide, metformin, or thiazolidinedione and, in the opinion of investigator, required further intensification of therapy, and (d) who had inadequate glycemic control $[\mathrm{HbA} 1 \mathrm{c} \geq 7.5 \%(58.5 \mathrm{mmol} / \mathrm{mol})$ and $\leq 12.0 \%(107.7 \mathrm{mmol} / \mathrm{mol})]$ at screening [10].

Major exclusion criteria were (a) patients who had severe hypoglycemia (more than one episode 6 months before study entry), (b) patients with excessive insulin resistance (receiving dose $>2.0 \mathrm{U} / \mathrm{kg}$ at the time of randomization), (c) patients who were obese [body mass index (BMI) $>45 \mathrm{~kg} / \mathrm{m}^{2}$ ], (d) patients who had cardiac diseases with functional status Class III or IV as per the New York Heart Association [11], (e) patients who had renal disorders [serum creatinine $\geq 135 \mu \mathrm{mol} / \mathrm{L}(1.5 \mathrm{mg} / \mathrm{dL})$ for men and $\geq 100 \mu \mathrm{mol} / \mathrm{L}(1.2 \mathrm{mg} / \mathrm{dL})$ for women], or (f) patients who had liver disease (alanine aminotransferase at least three times the upper normal limit of reference range) [10].

Eligible patients, based on inclusion and exclusion criteria, were randomized to receive either PPT or BBT, and either to an aggressive dosing algorithm (based on plasma glucose levels and total daily insulin) or a conservative dosing algorithm (plasma glucose levels). Patients randomized to the PPT group received insulin lispro mix 50/50 (50\% insulin lispro and $50 \%$ insulin lispro protamine suspension) three times daily before meals. If fasting blood glucose (FBG) targets were not achieved with insulin lispro mix 50/50, the evening preprandial dose could be changed to an injection of insulin lispro mix 75/25 (25\% insulin lispro and $75 \%$ insulin lispro protamine suspension). The starting dose was based on the insulin glargine total dose at study entry divided into three equal doses of lispro mix 50/50 before meals. Patients randomized to the BBT group received insulin glargine once daily along with preprandial insulin lispro. The starting dose of this regimen was also based on the total glargine dose at study entry, with $50 \%$ administered as glargine and the other 50\% given in three equal doses of lispro. Patients in both arms continued to receive OAMs; however, insulin secretagogues (sulfonylureas and meglitinides) were discontinued at randomization. The dose of insulin is decided with a goal of achieving preprandial blood glucose of less than $110 \mathrm{mg} /$ $\mathrm{dL}(6.11 \mathrm{mmol} / \mathrm{L})$ and a 2 -h postprandial blood glucose of less than $140 \mathrm{mg} / \mathrm{dL}(7.78 \mathrm{mmol} / \mathrm{L})$ with no hypoglycemia [blood glucose $<72 \mathrm{mg}$ / $\mathrm{dL}(4.0 \mathrm{mmol} / \mathrm{L})]$. Detailed study design, dosing schedule, dosing algorithm, efficacy, and safety results of this study were previously published [10].

All procedures followed were in accordance with the ethical standards of the responsible committee on human experimentation (institutional and national) and with the Helsinki Declaration of 1964, as revised in 2013. Informed consent was obtained from all patients for being included in the study.

\section{Statistical Analysis}

Of 547 patients who entered the study, 374 were randomized by an interactive telephone system at a 1:1 ratio to the PPT and BBT groups, respectively [10]. Of these 374 patients, data for 182 patients (81 on PPT and 101 on BBT) who provided a baseline HbA1c and achieved a target 24-week HbA1c [ $<7.0 \%(53.0 \mathrm{mmol} / \mathrm{mol})$; responders, also referred to as at-goal patients] were examined and explored. The data were analyzed by the SIDES algorithm [9], instead of specifying subgroup by anecdotal evidence, to explore a subgroup of patients (out of those 182 at-goal patients) who could show favorable responses to PPT.

The SIDES method, a novel recursive partitioning procedure, allows direct evaluation of the treatment effect in subgroups and is 
effective in evaluating modest-sized and large databases. This approach helps in searching for subgroups with a large differential effect relative to the study population. Also, this method can be applied as a part of prospectively defined tailored-therapy strategy and retrospectively throughout drug development across early- and late-phase trials combined to detect important predictive subgroups as early as possible [9]. The algorithm directly searches for large treatment effect simultaneously among many covariates. The traditional way of performing subgroup analyses involves prespecifying the subgroup of interests by specifying a set of variables and the corresponding cutoff points. The differences of treatment effects between comparator groups can then be examined by a parametric regression. Such an approach necessitates predefining subgroups of interests, which is often difficult when there are many covariates. Also, for any particular dataset, the subgroup suggested by our experience may not be the subgroup that had the maximal differential treatment effect. The SIDES algorithm instead allows the data to guide the process of identifying the subgroups, thus eliminating the need to predefine potential cutoff value. Insights suggested by data in this manner can provide insights that might not be evident on an a priori basis. This would provide a unique advantage for exploratory analyses, for which the primary interest is often to discover new evidence instead of confirming a priori hypotheses. The SIDES algorithm was implemented by a subgroup identification tool (SIT). This tool was developed by Eli Lilly and Company and was used to support the refinement of clinical development and post hoc analyses of study results [9]. Few studies using the SIDES method to identify subgroups of interest have already been published [12-15].

For the purposes of this analysis, the SIDES algorithm search criteria incorporated stratification by baseline $\mathrm{HbA1c}$ to control for the differences between patients in baseline HbA1c because it was well accepted that baseline HbA1c would have a direct effect on the change in HbA1c from baseline. Without this stratification, the search may likely end up with subgroups that have the largest difference in baseline HbA1c. The stratification levels used were quintiles estimated by the SIT for the distribution of baseline HbA1c for the 182 patients included in the analysis dataset. The variable importance score was calculated as the sum of the negative natural log of the splitting criterion [9] over all explored subgroups where the covariate was one of the splitters. It may be viewed as a measure of the relative importance; the covariate contributed to the subgroup identification process. It also provided a benchmark value computed using permutation-based maximum variable importance. To perform the permutation, first, the treatment labels for the 182 at-goal patients were randomly permuted. Second, new analyses using the SIDES algorithm were performed using the same set of covariates, and the maximum variable importance was recorded (this maximum variable importance may correspond to different covariate at different runs). These two steps were repeated 500 times which yielded 500 maximum variable importance scores. We then calculated the mean and standard deviation (SD) of those 500 scores and used them as a benchmark value. Covariates with variable importance greater than the mean of permutation-based maximum variable importance may be considered a strong indication for an important subgroup effect, and covariates with variable importance greater than the mean plus SD of permutation-based maximum variable importance may be considered a very strong indication of an important subgroup effect. The detailed statistical method was described in detail in Lipkovich et al. [9] and Hardin et al. [12].

All $p$ values were provided as a descriptive measure for the difference between treatments and were computed using a two-sample $t$ test for continuous variables and Fisher's exact test for categorical variables. Such summaries and comparisons were made between PPT and BBT treatment groups in the overall at-goal patients and in the identified subgroup.

Note that SIDES is just a data-mining algorithm that can efficiently explore the features of the observed data and provide a data-driven subgroup of interest. It does not alter the observed data, and the summaries and 
comparisons are generated using the common and conventional statistical tools.

\section{Outcome and Predictor Variables}

The outcome variable input into the SIT was change from baseline in $\mathrm{HbA1c}$ for patients who achieved control at 24 weeks $[<7.0 \%$ $(53.0 \mathrm{mmol} / \mathrm{mol})]$. This measure was used as the response variable for the subgroup identification analysis with the SIT, and the following variables were used as candidate predictors of treatment effect: baseline FBG (from self-monitored blood glucose), race/ethnicity, baseline morning 2-h postprandial glucose (from self-monitored blood glucose), duration of diabetes, age at study entry, gender, baseline BMI, baseline use of thiazolidinedione (Yes or No), baseline use of metformin (Yes or No), and randomized treatment. The SIT compared this change in HbA1c between the two groups to identify the subgroup that maximized the treatment difference (PPT versus BBT).

\section{RESULTS}

The demographics and characteristics of the at-goal patient population are presented in Table 1. All of the baseline characteristics were comparable between the treatment groups. A greater number of patients were male $(55.56 \%$ and 56.44\%) and Caucasian $(59.26 \%$ and $59.41 \%$ ) in the PPT and BBT groups, respectively. The mean (SD) age was 56.19 (9.84) and 54.88 (9.45) years with a mean (SD) baseline HbA1c of $8.46(0.73) \%$ and 8.67 (1.03)\% [69.0 (7.98) and $71.3(11.26) \mathrm{mmol} / \mathrm{mol}]$ in the PPT and BBT groups, respectively. At the end of the study, the mean (SD) total insulin dose was significantly higher for the BBT group compared to the PPT group $\left[\begin{array}{ll}1.37 & (0.88)\end{array}\right)$ versus 1.16 $(0.48) \mathrm{U} / \mathrm{kg} ; p=0.05]$. The mean (SD) increase in weight from baseline to endpoint was similar between treatment groups. The 30-day hypoglycemic rate (number of events) over the 24-week treatment period was similar between the PPT and BBT groups in the at-goal patients.

The variable importance score for all the covariates explored in the analyses is provided in Table 2. The mean (SD) permutation-based maximum variable importance value based on subgroup importance was 1.25 (0.54). Thus, values greater than 1.25 were considered strong subgroup variables in this analysis, and values greater than 1.79 were considered very strong variables. Race other than Caucasian and baseline FBG demonstrated values above the value identified by subgroup importance and are considered strong variables (Table 2). Race other than Caucasian and baseline FBG $<8.89 \mathrm{mmol} / \mathrm{L}$ defined the subgroup considered replicable. This subgroup was identified with a single training set comprised of all at-goal patients. As a point of reference, this subgroup was in the lower part of the distribution of FBG for the 182 patients. In the 182 at-goal patients, the median FBG was $9.00 \mathrm{mmol} / \mathrm{L}$, the 25 th percentile was $6.98 \mathrm{mmol} / \mathrm{L}$, and 75 th percentile was $11.39 \mathrm{mmol} / \mathrm{L}$.

The characteristics of the subgroup of at-goal patients $(n=42)$ with race other than Caucasian and FBG $(<8.89 \mathrm{mmol} / \mathrm{L})$ are presented in Table 3. The majority of patients were Hispanic $(66.67 \%)$ in both treatment groups. The mean (SD) age was $56.56(6.67)$ and $55.06(9.25)$ years in the PPT and BBT groups, respectively. The baseline HbA1c was similar in both groups with a mean (SD) HbA1c of $8.45(0.69) \%$ and 8.50 $(0.73) \%$ [68.9 (7.54) and $69.4(7.98) \mathrm{mmol} / \mathrm{mol}]$ in the PPT and BBT groups, respectively. The total insulin dose at endpoint [mean (SD)] was numerically less but not statistically different in the PPT group compared with BBT group [1.10 (0.39) versus $1.25(0.45) \mathrm{U} / \mathrm{kg}]$. The 30-day hypoglycemic rate over the 24 -week treatment period was similar in the PPT group compared to the BBT group in the subgroup of at-goal patients.

No significant difference in change in HbA1c from baseline to endpoint was reported between the treatment groups in the at-goal patient population. The mean (SD) decrease in HbA1c was numerically greater in the BBT group (Table 1; Fig. 1) in at-goal patients [PPT -2.17 (0.79)\% versus BBT -2.34 (1.00)\%; -23.7 (8.63) $\mathrm{mmol} / \mathrm{mol}$ versus $-25.6(10.93) \mathrm{mmol} / \mathrm{mol}$, whereas the decrease in HbA1c was numerically greater in the PPT group (Table 3; Fig. 1) in the subgroup of at-goal patients with race other 
Table 1 Demographics and characteristics of the at-goal (24 weeks) population (who provided a baseline glycated hemoglobin) in the trial

\begin{tabular}{|c|c|c|c|}
\hline \multirow[t]{2}{*}{ Variable } & \multicolumn{2}{|c|}{ Treatment group } & \multirow[t]{2}{*}{$p$ value } \\
\hline & $\overline{\mathrm{PPT}}(N=81)$ & BBT $(N=101)$ & \\
\hline Age (years), mean (SD) & $56.19(9.84)$ & $54.88(9.45)$ & $0.36^{\mathrm{a}}$ \\
\hline Gender, $n(\%)$ & & & $1.00^{\mathrm{b}}$ \\
\hline Male & $45(55.56)$ & $57(56.44)$ & \\
\hline Female & $36(44.44)$ & $44(43.56)$ & \\
\hline Race, $n(\%)$ & & & $0.97^{\mathrm{b}}$ \\
\hline African & $7(8.64)$ & $6(5.94)$ & \\
\hline Caucasian & $48(59.26)$ & $60(59.41)$ & \\
\hline East/Southeast Asian & $4(4.94)$ & $5(4.95)$ & \\
\hline Hispanic & $22(27.16)$ & $29(28.71)$ & \\
\hline Other & $0(0.0)$ & $1(0.99)$ & \\
\hline Baseline BMI $\left(\mathrm{kg} / \mathrm{m}^{2}\right)$, mean $(\mathrm{SD})$ & $35.42(5.29)$ & $34.61(5.62)$ & $0.32^{\mathrm{a}}$ \\
\hline Duration of diabetes (years), mean (SD) & $10.37(5.90)$ & $11.35(6.13)$ & $0.28^{\mathrm{a}}$ \\
\hline Baseline HbAlc (\%), mean (SD) & $8.46(0.73)^{c}$ & $8.67(1.03)$ & $0.10^{\mathrm{a}}$ \\
\hline Baseline HbAlc (mmol/mol), mean (SD) & $69.0(7.98)^{\mathrm{c}}$ & $71.3(11.26)$ & $0.10^{\mathrm{a}}$ \\
\hline Baseline FBG $(\mathrm{mmol} / \mathrm{L})$, mean $(\mathrm{SD})$ & $9.41(3.53)^{\mathrm{d}}$ & $9.71(3.52)$ & $0.57^{\mathrm{a}}$ \\
\hline Baseline weight $(\mathrm{kg})$, mean $(\mathrm{SD})$ & $103.80(21.47)$ & $99.69(22.31)$ & $0.21^{\mathrm{a}}$ \\
\hline Morning 2-h PPG $(\mathrm{mmol} / \mathrm{L})$, mean $(\mathrm{SD})$ & $14.91(4.23)^{\mathrm{d}}$ & $14.05(3.68)^{\mathrm{e}}$ & $0.15^{\mathrm{a}}$ \\
\hline Baseline OAMs, $n(\%)$ & & & $0.07^{\mathrm{b}}$ \\
\hline MET & $50(61.73)$ & $52(51.49)$ & \\
\hline TZD & $2(2.47)$ & $12(11.88)$ & \\
\hline $\mathrm{MET}+\mathrm{TZD}$ & $19(23.46)$ & $20(19.80)$ & \\
\hline None & $10(12.35)$ & $17(16.83)$ & \\
\hline Total insulin dose at endpoint $(\mathrm{U} / \mathrm{kg})$, mean $(\mathrm{SD})$ & $1.16(0.48)$ & $1.37(0.88)^{\mathrm{f}}$ & $0.05^{\mathrm{a}^{*}}$ \\
\hline Weight at endpoint (kg), mean (SD) & $108.3(22.37)$ & $104.3(23.62)$ & $0.24^{a}$ \\
\hline Change in weight from baseline $(\mathrm{kg})$, mean $(\mathrm{SD})$ & $4.53(4.78)$ & $4.59(4.25)$ & $0.93^{\mathrm{a}}$ \\
\hline Change in HbAlc from baseline (\%), mean (SD) & $-2.17(0.79)^{\mathrm{c}}$ & $-2.34(1.01)$ & $0.19^{\mathrm{a}}$ \\
\hline Change in $\mathrm{HbAlc}$ from baseline $(\mathrm{mmol} / \mathrm{mol})$, mean $(\mathrm{SD})$ & $-23.7(8.63)^{c}$ & $-25.6(10.93)$ & $0.19^{\mathrm{a}}$ \\
\hline Change in FBG from baseline (mmol/L), mean (SD) & $-1.58(3.32)^{\mathrm{c}}$ & $-2.04(3.35)^{\mathrm{g}}$ & $0.37^{\mathrm{a}}$ \\
\hline
\end{tabular}


Table 1 continued

\begin{tabular}{llll}
\hline Variable & Treatment group & $\boldsymbol{p}$ value \\
\cline { 2 - 4 } & PPT $(\boldsymbol{N}=\mathbf{8 1})$ & BBT $(\boldsymbol{N}=\mathbf{1 0 1})$ & \\
\hline 30-day hypoglycemic rate (number of events), mean (SD) & $5.31(4.20)$ & $5.09(4.11)$ & $0.72^{\mathrm{a}}$ \\
\hline
\end{tabular}

$B B T$ basal-bolus therapy, $B M I$ body mass index, $F B G$ fasting blood glucose, $H b A 1 c$ glycated hemoglobin, $M E T$ metformin, $N$ number of patients in each group, $n$ number of affected patients, $O A M$ oral antihyperglycemic medications, $P P G$ postprandial glucose, $P P T$ prandial premixed therapy, $S D$ standard deviation, $T Z D$ thiazolidinedione

${ }^{*} p \leq 0.05$

${ }^{\mathrm{a}} p$ values are from two-sample $t$ test with Satterthwaite approximation. $p$ values are intended as descriptive measure only

b $p$ values are from Fisher's exact test. $p$ values are intended as descriptive measure only

c $n=78$

d $n=80$

e $n=98$

f $n=100$

g $n=92$

Table 2 Variable importance score based on subgroup significance

\begin{tabular}{ll}
\hline Variable & $\begin{array}{l}\text { Importance score based } \\
\text { on subgroup significance }\end{array}$ \\
\hline Baseline FBG & $\mathbf{2 . 3 6}$ \\
Race/ethnicity & $\mathbf{1 . 4 0}$ \\
Morning PPG & 1.07 \\
Duration of diabetes & 0 \\
Age & 1.23 \\
Gender & 0.28 \\
Baseline BMI & 0.75 \\
Baseline TZD & 0 \\
Baseline MET & 0 \\
Permutation-based maximum & 1.25 \\
variable importance (mean) & \\
Permutation-based maximum & 0.54 \\
variable importance (SD) & \\
\hline
\end{tabular}

Importance scores greater than mean plus SD of the permutation-based maximum variable importance is highlighted in bold

$B M I$ body mass index, $F B G$ fasting blood glucose, $M E T$ metformin, $P P G$ postprandial glucose, $S D$ standard deviation, $T Z D$ thiazolidinedione than Caucasian and FBG $<8.89 \mathrm{mmol} / \mathrm{L}$ [PPT $-2.27(0.88) \%$ versus BBT: $-2.05 \quad(0.75) \%$; -24.8 (9.62) $\mathrm{mmol} / \mathrm{mol}$ versus $-22.4(8.20)$ $\mathrm{mmol} / \mathrm{mol}$. Although reduction in $\mathrm{HbA} 1 \mathrm{c}$ was not statistically significant between PPT and BBT groups, the trend reversed in the identified subgroup.

In at-goal patients, the baseline and endpoint mean (SD) FBG were 9.41 (3.53) and 7.71 (1.43) $\mathrm{mmol} / \mathrm{L}$ in the PPT group; and 9.71 (3.52) and $7.48(1.86) \mathrm{mmol} / \mathrm{L}$ in the BBT group. The mean (SD) change in FBG in the PPT group was $-1.58(3.32) \mathrm{mmol} / \mathrm{L}$ and in BBT group was -2.04 (3.35) mmol/L (Table 1; Fig. 2). In the subgroup of at-goal patients, the baseline and endpoint mean (SD) FBG were 6.81 (1.23) and $6.95(1.52) \mathrm{mmol} / \mathrm{L}$ in the PPT group; and 6.59 (1.57) and 7.13 (1.88) $\mathrm{mmol} / \mathrm{L}$ in the BBT group. The mean (SD) change in FBG was 0.15 (1.94) $\mathrm{mmol} / \mathrm{L}$ in the PPT group and 0.54 (2.23) $\mathrm{mmol} / \mathrm{L}$ in BBT group (Table 3; Fig. 2). This method of subgroup identification is robust and identified the subgroup of at-goal patients with race other than Caucasian and FBG $<8.89 \mathrm{mmol} / \mathrm{L}$ in a sensitivity analysis by adding average blood glucose excursions as an additional candidate predictor variable (data not shown). 
Table 3 Demographics and characteristics of at-goal (24 weeks) population (who provided a baseline glycated hemoglobin) subgroup with race other than Caucasian and baseline fasting blood glucose $(<8.89 \mathrm{mmol} / \mathrm{L})$ in the trial

\begin{tabular}{|c|c|c|c|}
\hline \multirow[t]{2}{*}{ Variable } & \multicolumn{2}{|c|}{ Treatment group } & \multirow[t]{2}{*}{$p$ value } \\
\hline & $\overline{\operatorname{PPT}(N=21)}$ & BBT $(N=21)$ & \\
\hline Age (years), mean (SD) & $56.56(6.67)$ & $55.06(9.25)$ & $0.55^{\mathrm{a}}$ \\
\hline Gender, $n(\%)$ & & & $1.00^{\mathrm{b}}$ \\
\hline Male & $9(42.86)$ & $10(47.62)$ & \\
\hline Female & $12(57.14)$ & $11(52.38)$ & \\
\hline Race, $n(\%)$ & & & $1.00^{\mathrm{b}}$ \\
\hline African & $4(19.05)$ & $3(14.29)$ & \\
\hline Caucasian & $0(0)$ & $0(0.0)$ & \\
\hline East/Southeast Asian & $3(14.29)$ & $4(19.05)$ & \\
\hline Hispanic & $14(66.67)$ & $14(66.67)$ & \\
\hline Other & $0(0)$ & $0(0)$ & \\
\hline Baseline BMI $\left(\mathrm{kg} / \mathrm{m}^{2}\right)$, mean $(\mathrm{SD})$ & $32.26(5.21)$ & $29.68(4.62)$ & $0.10^{\mathrm{a}}$ \\
\hline Duration of diabetes (years), mean (SD) & $10.90(7.27)$ & $14.29(6.79)$ & $0.13^{\mathrm{a}}$ \\
\hline Baseline HbAlc (\%), mean (SD) & $8.45(0.69)$ & $8.50(0.73)$ & $0.81^{a}$ \\
\hline Baseline $\mathrm{HbAlc}(\mathrm{mmol} / \mathrm{mol})$, mean $(\mathrm{SD})$ & $68.9(7.54)$ & $69.4(7.98)$ & $0.81^{a}$ \\
\hline Baseline FBG $(\mathrm{mmol} / \mathrm{L})$, mean $(\mathrm{SD})$ & $6.81(1.23)$ & $6.59(1.57)$ & $0.62^{\mathrm{a}}$ \\
\hline Baseline weight $(\mathrm{kg})$, mean $(\mathrm{SD})$ & $87.18(18.16)$ & $81.38(15.15)$ & $0.27^{\mathrm{a}}$ \\
\hline Morning 2-h PPG (mmol/L), mean (SD) & $14.27(3.82)^{\mathrm{c}}$ & $13.78(2.94)$ & $0.65^{\mathrm{a}}$ \\
\hline Baseline OAMs, $n$ (\%) & & & $0.38^{\mathrm{b}}$ \\
\hline MET & $12(57.14)$ & $9(42.86)$ & \\
\hline TZD & $1(4.76)$ & $1(4.76)$ & \\
\hline $\mathrm{MET}+\mathrm{TZD}$ & $5(23.81)$ & $3(14.29)$ & \\
\hline None & $3(14.29)$ & $8(38.10)$ & \\
\hline Total insulin dose at endpoint (U/kg), mean (SD) & $1.10(0.39)$ & $1.25(0.45)$ & $0.26^{\mathrm{a}}$ \\
\hline Weight at endpoint $(\mathrm{kg})$, mean $(\mathrm{SD})$ & $90.69(18.70)$ & $85.12(15.80)$ & $0.30^{\mathrm{a}}$ \\
\hline Change in weight from baseline $(\mathrm{kg})$, mean $(\mathrm{SD})$ & $3.51(3.89)$ & $3.75(3.29)$ & $0.83^{\mathrm{a}}$ \\
\hline Change in HbAlc from baseline (\%), mean (SD) & $-2.27(0.88)$ & $-2.05(0.75)$ & $0.40^{\mathrm{a}}$ \\
\hline Change in HbAlc from baseline ( $\mathrm{mmol} / \mathrm{mol})$, mean (SD) & $-24.8(9.62)$ & $-22.4(8.20)$ & $0.40^{\mathrm{a}}$ \\
\hline
\end{tabular}


Table 3 continued

\begin{tabular}{llll}
\hline Variable & Treatment group & $\boldsymbol{p}$ value \\
\cline { 2 - 3 } & PPT $(\boldsymbol{N}=\mathbf{2 1})$ & BBT $(\boldsymbol{N}=\mathbf{2 1})$ \\
\hline Change in FBG from baseline (mmol/L), mean (SD) & $0.15(1.94)$ & $0.54(2.23)$ & $0.55^{\mathrm{a}}$ \\
30-day hypoglycemic rate (number of events), mean (SD) & $7.24(5.26)$ & $5.80(3.82)$ & $0.31^{\mathrm{a}}$ \\
\hline
\end{tabular}

$B B T$ basal-bolus therapy, $B M I$ body mass index, $F B G$ fasting blood glucose, $H b A 1 c$ glycated hemoglobin, $M E T$ metformin, $N$ number of patients in each group, $n$ number of affected patients, $O A M$ oral antihyperglycemic medications, $P P G$ postprandial glucose, $P P T$ prandial premixed therapy, $S D$ standard deviation, $T Z D$ thiazolidinedione

${ }^{\mathrm{a}} p$ values are from two-sample $t$ test with Satterthwaite approximation. $p$ values are intended as descriptive measure only

b $p$ values are from Fisher's exact test. $p$ values are intended as descriptive measure only

c $n=20$

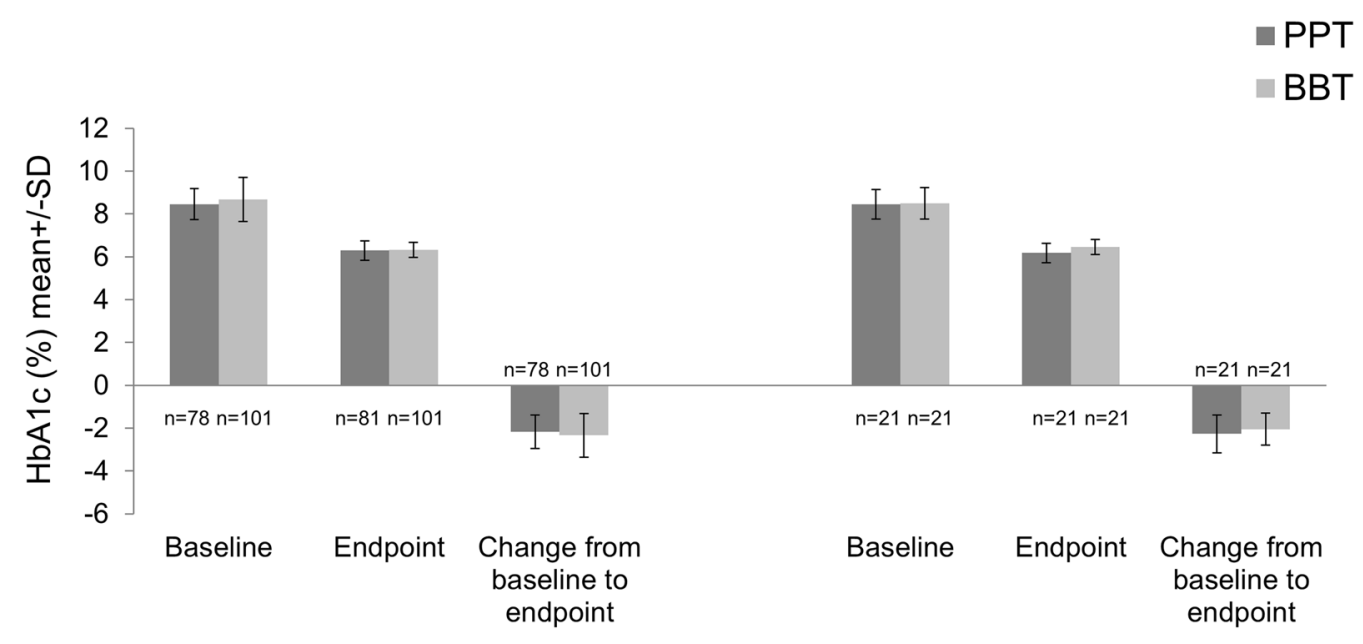

At-goal patients

Subgroup of at-goal patients

Fig. $1 \mathrm{HbAlc}$ at baseline, endpoint, and change from baseline to endpoint (24 weeks of treatment) in both at-goal patients and subgroup of at-goal patients. $B B T$

\section{DISCUSSION}

The goal of this analysis was to provide preliminary information suitable for insulin intensification therapy. This post hoc analysis used the SIDES algorithm to identify the subgroups that benefitted most from different insulin intensification therapies (PPT versus BBT).

As a result of the progressive diminution in insulin secretory capacity, patients will eventually require insulin intensification therapy by adding prandial insulin to basal insulin (BBT) or basal-bolus therapy, $H b A 1 c$ glycated hemoglobin, $n$ number of patients without missing data, $P P T$ prandial premixed therapy

by switching to premixed insulins [16]. Basal-bolus therapy is often considered to be the gold standard in achieving target goals of glycemic control. However, evidence suggests that thrice-daily premixed insulin could be an alternative to BBT [17]. The pharmacodynamics, as measured by glucose infusion rates, is similar between these two regimens [18]. Also, a recent systemic review of 13 randomized clinical trials comparing the effects of basal-bolus and premixed insulin regimens in patients with T2DM who had not responded to previous antidiabetes medications showed that premixed 


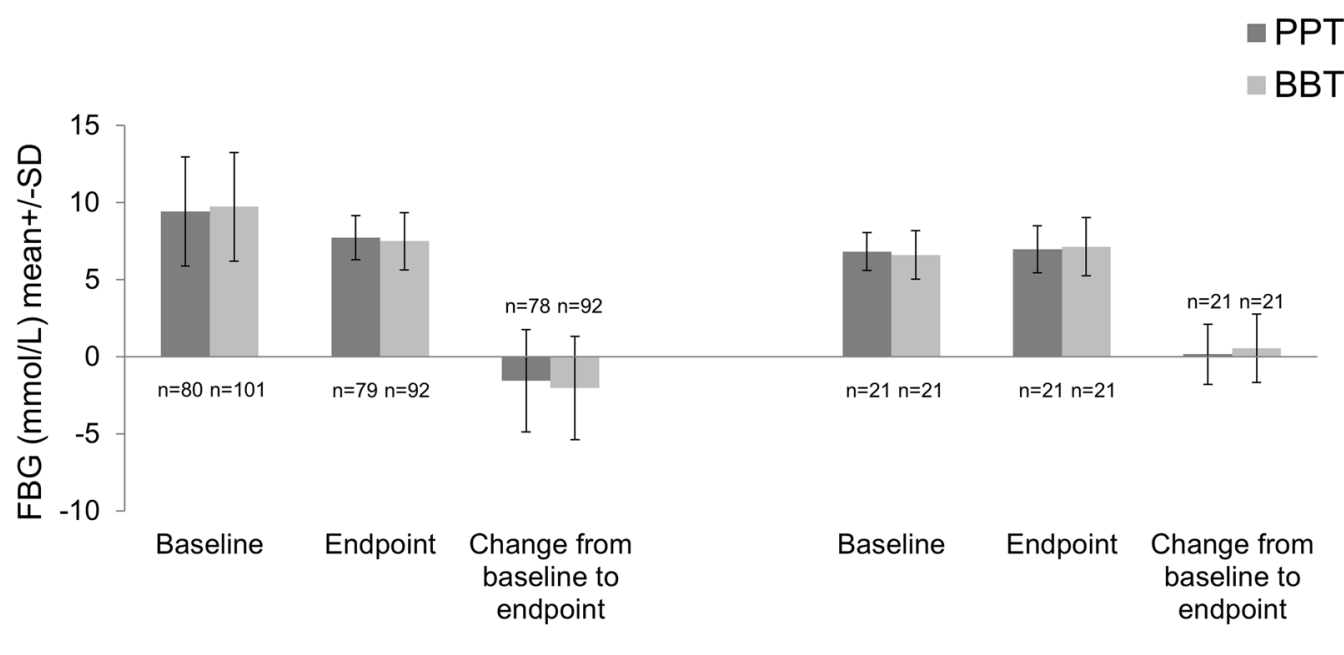

At-goal patients

Subgroup of at-goal patients

Fig. 2 FBG at baseline, endpoint, and change from baseline to endpoint ( 24 weeks of treatment) in both at-goal patients and subgroup of at-goal patients. $B B T$

insulins are noninferior to basal-bolus regimens with respect to reduction of HbA1c from baseline, with similar rates of hypoglycemia, weight change, and daily insulin dose. Meta-analysis of change in HbA1c level between basal-bolus and premixed insulin regimens result in a small and nonsignificant difference of $0.09 \% \quad(95 \%$ CI -0.03 to 0.21 ) [19]. Thus, to mix or to separate the insulins for the correct patient is still an important clinical question.

Our study revealed that patients with both race other than Caucasian and FBG $<8.89 \mathrm{mmol} / \mathrm{L}$ may have a different response to intensification therapies compared to the at-goal patient population. The numerically larger decrease in HbA1c in the PPT group compared to the BBT group in the subgroup of at-goal patients than total at-goal patients indicated that subgroup patients responded better than at-goal patients with the PPT regimen.

Though evidence showed the role of genetic susceptibility, thrifty phenotype, diet, and lifestyle in development of diabetes with racial disparities, evidence evaluating the effect of race on the efficacy of certain insulin regimens is limited [2, 20-23]. From the pathophysiology perspective, impaired beta cell function and insulin resistance are important in the basal-bolus therapy, $F B G$ fasting blood glucose, $n$ number of patients without missing data, $P P T$ prandial premixed therapy

development of diabetes [24]. Some studies showed that Hispanic and African population may be more susceptible to T2DM and more insulin resistant, although they have greater insulin secretion ability [25-27], while development of diabetes in the East Asian population is characterized by early beta cell dysfunction and insulin resistance $[20,28]$. In the identified subgroup of patients, most of the patients belong to the Hispanic race; African and East Asian patients were of small proportion. Most of the clinical trials evaluating the efficacy of insulins were conducted in Caucasians and the racial diverse data are limited. A post hoc pooled analysis of 11 multinational clinical trials explored the impact of race/ethnicity on the efficacy and safety of commonly used insulin regimens. The analyses showed that patients of Latino/Hispanic, Asian, and African descent had different responses to insulin therapy: Latino/ Hispanic patients had greater glycemic improvement than Caucasians with once-daily basal insulin treatment, while Caucasians had better glycemic control than Latino/Hispanic and Asian patients with twice-daily premix insulin therapy. For premixed insulin thrice-daily therapy, the HbA1c control was comparable across patients groups [29], but there was no information related to BBT. Also, a 
recently conducted systematic review supported the use of premixed insulins as an initiation and intensification regimen in East Asian patients, indicating that the efficacy profile of premixed insulins is similar to that of other insulin treatments [30].

The FBG plays a very important role in overall glycemic control [31, 32]. On the trial level, more than half of the patients switched from evening insulin lispro mix 50/50 to insulin lispro mix 75/25 [10]. A recently published study compared the treatment effects of insulin lispro mix thrice daily (insulin lispro mix 50 before breakfast and lunch plus insulin lispro mix 25 before dinner) with BBT in East Asian patients with T2DM who were inadequately controlled with twice-daily premixed insulin. The results showed that premixed insulin lispro mix thrice daily was noninferior to BBT in the East Asian population, and the frequency of adverse events and the incidences of overall and nocturnal hypoglycemia were comparable between groups [17]. If FBG could not be controlled by the mid mixture, the evening injection should be switched to low mixture. The identified subgroup (race other than Caucasian and lower baseline FBG level) responded better to PPT treatment; the reason might be that the insulin lispro protamine suspension in premix was enough to control the FBG levels, and the patients could benefit from this simplified insulin intensification therapy with fewer injections.

Insulin intensification is not a one-way process. According to the American Diabetes Association/European Association for the Study of Diabetes (ADA/EASD) statement, it is important to individualize treatment targets and treatment strategies with an emphasis on a patient-centered approach while making treatment decisions [16]. The important aspects to consider while choosing or titrating insulin intensification regimens, according to the ADA/ EASD statement, are the number of injections needed and the complexity and flexibility of the regimens [16]. For patients who wanted to limit the number of injections per day, premixed insulins remained the preferable option because of convenience of administration [33, 34]. Nonadherence to insulin therapy is the major reason for worsening of glycemic control [35]. Nonadherence to insulin therapy also depends on perceived burden of insulin therapy [36], which may lead to increased risk of long-term complications [37-39]. Fewer injections might promote patients' adherence to the treatment. Because premixed insulins require few injections, PPT may potentially improve treatment adherence. Although premixed insulin analogues are more convenient, they are less adaptable because of their inability to titrate the shorter- from the longer-acting components of the formulation. However, these proved to be a viable treatment option owing to their less-complicated injection schedule and need of fewer injections [4].

There are some limitations for consideration in this analysis. First, the present results are a post hoc analysis of a study that compared two intensive insulin regimens in patients who failed on basal insulin plus OAM therapy [10]. Second, in the identified subgroup, though patients treated with the premixed, thrice-daily regimen had a numerically larger decrease in HbA1c than with the basal-bolus regimen, the results were not statistically significant. The nonsignificance may be due to the small sample size of only 42 patients in the identified group. However, our study sought to explain the heterogeneity and provided a preliminary hypothesis for tailored individualized therapy. The analysis was exploratory in nature and may need to be further confirmed with other prevailing evidence or future studies. Third, the SIDES algorithm extensively explores the structure of the observed data and identifies a differentiate group suggested by the data. The advantage of this novel statistical tool is that the result is driven by data, without any human intervention. However, with a different set of study data, a separate group may have been identified. If possible, this tool could be used in a large dataset to test and validate the hypothesis.

\section{CONCLUSIONS}

In the present post hoc analysis, a preliminary hypothesis of patient segmentation that will get the maximum benefit from insulin 
intensification regimens was identified. Patients with both race other than Caucasian and lower levels of FBG were identified as the subgroup that might benefit from a premixed thrice-daily regimen. Though this subgroup analysis provides some information for tailored patient-centered therapy, it needs further exploration in future prospective, randomized trials.

\section{ACKNOWLEDGEMENTS}

This study along with article processing charges was sponsored by Eli Lilly and Company, Shanghai, China. Eli Lilly and Company was involved in the study design, data collection, data analysis, and preparation of the manuscript. The authors would like to thank Pavan Yenduri and Angela Lorio of inVentiv Health Clinical for their assistance in drafting, editing, and final proofreading of the paper. Support for this assistance was funded by Eli Lilly and Company. The authors also thank Yun Chen and Li Shen of Eli Lilly and Company for their support in peer review. The authors also thank Fei Li of Eli Lilly and Company for assistance in publication project management. The authors would like to thank all study investigators and participants involved in the study. All named authors meet the International Committee of Medical Journal Editors (ICMJE) criteria for authorship for this manuscript, take responsibility for the integrity of the work as a whole, and have given final approval to the version to be published. All authors had full access to all of the data in this study and take complete responsibility for the integrity of the data and accuracy of the data analysis. Li Xin Shi was involved in the interpretation of data for the work. Peng Fei Li was involved in the analysis and interpretation of data for the work. Jia Ning Hou was involved in the conception, design, and interpretation of data for the work. All authors were involved in critical revision of the manuscript.

Disclosures. Li Xin Shi has nothing to disclose. Peng Fei Li is an employee of Eli Lilly and Company. Jia Ning Hou is an employee of Eli Lilly and Company.
Compliance with Ethics Guidelines. All procedures followed were in accordance with the ethical standards of the responsible committee on human experimentation (institutional and national) and with the Helsinki Declaration of 1964, as revised in 2013. Informed consent was obtained from all patients for being included in the study.

Data Availability. The datasets generated during and/or analyzed during the current study are available from the corresponding author on reasonable request.

Open Access. This article is distributed under the terms of the Creative Commons Attribution-NonCommercial 4.0 International License (http://creativecommons.org/licenses/ by-nc/4.0/), which permits any noncommercial use, distribution, and reproduction in any medium, provided you give appropriate credit to the original author(s) and the source, provide a link to the Creative Commons license, and indicate if changes were made.

\section{REFERENCES}

1. International Diabetes Federation. IDF diabetes atlas, 7th edn. Brussels (Belgium): International Diabetes Federation, 2013. http://www.idf.org/ diabetesatlas. Accessed 24 Feb 2015.

2. Hu FB. Globalization of diabetes: the role of diet, lifestyle, and genes. Diabetes Care. 2011;34:1249-57.

3. Handelsman Y, Bloomgarden ZT, Grumberger G, et al. American Association of Clinical Endocrinologists and American College of Endocrinologyclinical practice guidelines for developing a diabetes mellitus comprehensive care plan-2015. Endocr Pract. 2015;21(Suppl 1):1-87.

4. Mosenzon O, Raz I. Intensification of insulin therapy for type 2 diabetic patients in primary care: basal-bolus regimen versus premix insulin analogs: when and for whom? Diabetes Care. 2013;36(Suppl 2):S212-8.

5. American Diabetes Association. Pharmacologic approaches to glycemic treatment. Diabetes Care. 2017;40(Suppl 1):S64-74.

6. Cantrell RA, Alatorre CI, Davis EJ, et al. A review of treatment response in type 2 diabetes: assessing the 
role of patient heterogeneity. Diabetes Obes Metab. 2010;12:845-57.

7. Klonoff DC. Personalized medicine for diabetes. J Diabetes Sci Technol. 2008;2:335-41.

8. Inzucchi SE, Bergenstal RM, Buse JB, et al. Management of hyperglycemia in type 2 diabetes, 2015: a patient-centered approach: update to a position statement of the American Diabetes Association and the European Association for the Study of Diabetes. Diabetes Care. 2015;38:140-9.

9. Lipkovich I, Dmitrienko A, Denne J, Enas G. Subgroup identification based on differential effect search-a recursive partitioning method for establishing response to treatment in patient subpopulations. Stat Med. 2011;30:2601-21.

10. Rosenstock J, Ahmann AJ, Colon G, Scism-Bacon J, Jiang H, Martin S. Advancing insulin therapy in type 2 diabetes previously treated with glargine plus oral agents: prandial premixed (insulin lispro protamine suspension/lispro) versus basal/bolus (glargine/lispro) therapy. Diabetes Care. 2008;31:20-5.

11. The Criteria Committee of the New York Heart Association. Functional capacity and objective assessment. Nomenclature and criteria for diagnosis of diseases of the heart and great vessels. 9th ed. Boston, MA: Little Brown; 1994.

12. Hardin DS, Rohwer RD, Curtis BH, et al. Understanding heterogeneity in response to antidiabetes treatment: a post hoc analysis using SIDES, a subgroup identification algorithm. J Diabetes Sci Technol. 2013;7:420-30.

13. Mori E, Ikeda M, Nakagawa M, Miyagishi H, Kosaka K. Pretreatment cognitive profile likely to benefit from donepezil treatment in dementia with Lewy bodies: pooled analyses of two randomized controlled trials. Dement Geriatr Cogn Disord. 2016;41:58-68.

14. Seibold H, Zeileis A, Hothorn T. Model-based recursive partitioning for subgroup analyses. Int J Biostat. 2016;12:45-63.

15. Patel S, Hee SW, Mistry D, et al. Identifying back pain subgroups: developing and applying approaches using individual patient data collected with clinical trials. Southampton (UK): NIHR Journals Library; 2016 Jul. Programme Grants for Applied Research, No. 4.10.

16. Inzucchi SE, Bergenstal RM, Buse JB, et al. Management of hyperglycemia in type 2 diabetes: a patient-centered approach: position statement of the American Diabetes Association (ADA) and the European Association for the Study of Diabetes (EASD). Diabetes Care. 2012;35:1364-79.
17. Jia W, Xiao X, Ji Q, et al. Comparison of thrice-daily premixed insulin (insulin lispro premix) with basal-bolus (insulin glargine once-daily plus thrice-daily prandial insulin lispro) therapy in East Asian patients with type 2 diabetes insufficiently controlled with twice-daily premixed insulin: an open-label, randomised, controlled trial. Lancet Diabetes Endocrinol. 2015;3:254-62.

18. Heise T, Heinemann L, Hovelmann U, et al. Pharmacokinetics and pharmacodynamics compared with once-daily biphasic human insulin and basal-bolus therapy. Diabetes Care. 2009;32:1431-3.

19. Giugliano D, Chiodini P, Maiorino MI, Bellastella $\mathrm{G}$, Esposito K. Intensification of insulin therapy with basal-bolus or premixed insulin regimens in type 2 diabetes: a systematic review and meta-analysis of randomized controlled trials. Endocrine. 2016;51:417-28.

20. Ma RC, Chan JC. Type 2 diabetes in East Asians: similarities and differences with populations in Europe and the United States. Ann N Y Acad Sci. 2013;1281:64-91.

21. Herman WH, Dungan KM, Wolffenbuttel BH, et al. Racial and ethnic differences in mean plasma glucose, hemoglobin A1c, and 1,5-anhydroglucitol in over 2000 patients with type 2 diabetes. J Clin Endocrinol Metab. 2009;94:1689-94.

22. Kirk JK, Passmore LV, Bell RA, et al. Disparities in A1C levels between Hispanic and non-Hispanic white adults with diabetes: a meta-analysis. Diabetes Care. 2008;31:240-6.

23. Lanting LC, Joung IM, Mackenbach JP, Lamberts SW, Bootsma AH. Ethnic differences in mortality, end-stage complications, and quality of care among diabetic patients: a review. Diabetes Care. 2005;28:2280-8.

24. Cerf ME. Beta cell dysfunction and insulin resistance. Front Endocrinol (Lausanne). 2013;4:37.

25. Haffner SM, Howard G, Mayer E, et al. Insulin sensitivity and acute insulin response in African-Americans, non-Hispanic whites, and Hispanics with NIDDM: the Insulin Resistance Atherosclerosis Study. Diabetes. 1997;46:63-9.

26. Kodama K, Tojjar D, Yamada S, Toda K, Patel CJ, Butte AJ. Ethnic differences in the relationship between insulin sensitivity and insulin response: a systematic review and meta-analysis. Diabetes Care. 2013;36:1789-96.

27. Osei K, Schuster DP. Ethnic differences in secretion, sensitivity, and hepatic extraction of insulin in 
black and white Americans. Diabet Med. 1994;11:755-62.

28. Kuroe A, Fukushima M, Usami M, et al. Impaired beta-cell function and insulin sensitivity in Japanese subjects with normal glucose tolerance. Diabetes Res Clin Pract. 2003;59:71-7.

29. Davidson JA, Lacaya LB, Jiang $H$, et al. Impact of race/ethnicity on the efficacy and safety of commonly used insulin regimens: a post hoc analysis of clinical trials in type 2 diabetes mellitus. Endocr Pract. 2010;16:818-28.

30. Sheu WH, Ji L, Lee WJ, Jabbar A, Han JH, Lew T. Efficacy and safety of premixed insulin analogs in Asian patients with type 2 diabetes: a systematic review. J Diabetes Investig. 2016. doi:10.1111/jdi. 12605.

31. Monnier L, Lapinski H, Colette C. Contributions of fasting and postprandial plasma glucose increments to the overall diurnal hyperglycemia of type 2 diabetic patients: variations with increasing levels of HbA(1c). Diabetes Care. 2003;26:881-5.

32. Riddle M, Umpierrez G, DiGenio A, Zhou R, Rosenstock J. Contributions of basal and postprandial hyperglycemia over a wide range of A1C levels before and after treatment intensification in type 2 diabetes. Diabetes Care. 2011;34:2508-14.
33. Garber AJ. Premixed insulin analogues for the treatment of diabetes mellitus. Drugs. 2006;66:31-49.

34. Dunbar JM, Madden PM, Gleeson DT, Fiad TM, McKenna TJ. Premixed insulin preparations in pen syringes maintain glycemic control and are preferred by patients. Diabetes Care. 1994;17:874-8.

35. Peyrot $\mathrm{M}$, Barnett $\mathrm{AH}$, Meneghini LF, Schumm-Draeger PM. Insulin adherence behaviours and barriers in the multinational global attitudes of patients and physicians in insulin therapy study. Diabet Med. 2012;29:682-9.

36. Peyrot M, Rubin RR, Kruger DF, Travis LB. Correlates of insulin injection omission. Diabetes Care. 2010;33:240-5.

37. American Diabetes Association. Standards of medical care in diabetes-2013. Diabetes Care. 2013;36(Suppl 1):S11-66.

38. Ho PM, Rumsfeld JS, Masoudi FA, et al. Effect of medication nonadherence on hospitalization and mortality among patients with diabetes mellitus. Arch Intern Med. 2006;166:1836-41.

39. Bailey CJ, Kodack M. Patient adherence to medication requirements for therapy of type 2 diabetes. Int J Clin Pract. 2011;65:314-22. 